\title{
Research on the intelligent control method of wind turbine grid connection without load
}

\author{
Jing Ren ${ }^{1}$ and Shudong Wang ${ }^{1}$ \\ ${ }^{1}$ College of Electrical and Information Engineering, Lanzhou University of Technology, Lanzhou, Gansu, 730050, China
}

\begin{abstract}
Aiming at the problem that some wind turbines are difficult to achieve stability and low fitting accuracy when they are connected to the grid, an intelligent control method of wind turbine is proposed. Intelligent control is designed, and the output of the control object is the same as the expected output. The initial fuzzy control rules are obtained by the nearest neighbour clustering algorithm and the rules are optimized by the neural network. The fuzzy control and control strategy are integrated to realize the intelligent control of wind turbine with no load. Experiment results show that: compared with conventional control method, the intelligent control method of no-load grid-connection reaches a stable state sooner. The quadratic sum of fitting errors of the intelligent control method is lower than that of the conventional control method, which indicates that the intelligent control method has a higher fitting precision for samples, and the effect is better when the fan is connected to the grid without load.
\end{abstract}

\section{Introduction}

All aspects of human production and life involve energy use. With the development of society and economy, the demand for energy for human production and life is increasing day by day. In China's energy supply structure, coal, oil and other non-renewable energy accounts for a considerable part. The extensive use of such energy sources not only causes serious environmental pollution, but also causes exhaustion of energy resources, leading to a prominent contradiction between the development situation and environmental pollution. Therefore, we must step up efforts to develop new energy and renewable energy, relieve the pressure of non-renewable energy, optimize the overall structure of energy, and develop and utilize new energy. Various forms of energy can be transformed into each other. Wind energy is the kinetic energy of air flow. Windmills can be used to extract wind energy to push large generators to work, and the electricity generated is connected to the power system [1]. Wind power generation is the large-scale wind turbine into the grid operation, generator and power system electrical connection, power exchange. Due to the random change of wind speed in the wind turbine, the unstable current generated during grid connection due to the abnormal rotor speed will cause a large change in the grid voltage, resulting in too slow response speed for grid connection, resulting in unstable operation and more likely to damage the generator. Using intelligent control method, control interconnection of wind turbine is analyzed. Through the study of power, the control rules are stored in the rule base in the form of rule set, which optimizes the control rules, reduces the power output ripple, improves the effect of intelligent control, and has the ability of real-time learning, so as to realize the intelligent control of no-load grid connected wind turbine.

\section{Design of intelligent control method for no-load grid-connected wind turbine}

The design process of no-load grid-connected intelligent control method for wind turbine includes intelligent control design, optimization of control rules and realization of three parts of intelligent control. The design process of intelligent control method is shown in figure 1 .

*Corresponding author's e-mail: renjing2005cqu18@163.com 


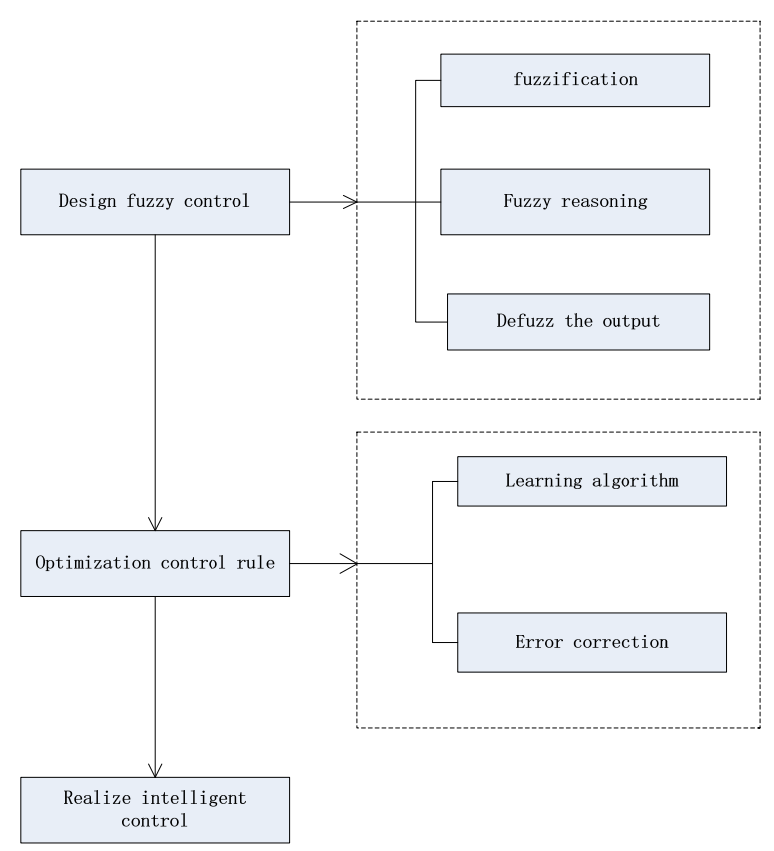

\section{1 intelligent control design}

Since no-load grid-connection has nonlinear objects with multiple inputs and outputs, in order to better control the no-load grid-connection of wind turbine units, intelligent control is used to describe the relationship between multiple variables [2], so that the output of the controlled object is the same as the expected output. Using intelligent control to adjust the power, so that the variable pitch actuator can operate at a variable speed in time. The intelligent control principle of variable propeller power is shown in figure 2 .

Figure 1 Design drawing of intelligent control method

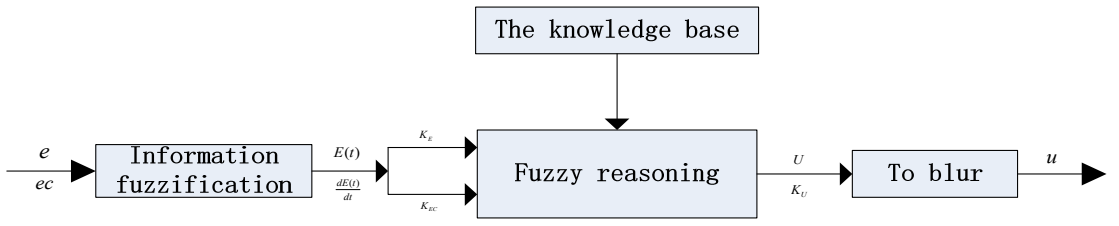

Figure 2 Schematic diagram of intelligent control

The wind generator set power output $\mathrm{P}_{0}$, rated power for $\mathrm{P}_{\mathrm{E}}$, power error $\mathrm{e}=\Delta \mathrm{P}=\mathrm{P}_{0}-\mathrm{P}_{\mathrm{E}}$, error rate $\mathrm{e} \mathrm{c}$ as input variables, $\mathrm{u}$ as output variables. The exact values e and $\mathrm{e}$ $\mathrm{c}$ were quantified as e and e c by the quantization factors $\mathrm{K}_{\mathrm{E}}$ and $\mathrm{K}_{\mathrm{EC}}$. Let $\mathrm{E}(\mathrm{t})\left(-\mathrm{X}_{\mathrm{E}}, \mathrm{X}_{\mathrm{E}}\right)$ be the basic domain of the input variable $\mathrm{E}, \mathrm{d} \mathrm{E}(\mathrm{t}) / \mathrm{d} \mathrm{t}\left(-\mathrm{X}_{\mathrm{EC}}, \mathrm{X}_{\mathrm{EC}}\right)$ be the basic domain of the input variable e $\mathrm{c}$, and the basic domain of the output variable $\mathrm{u}$ be $\left(-\mathrm{X}_{\mathrm{U}}, \mathrm{X}_{\mathrm{U}}\right)$. According to the data, the input quantization factors $\mathrm{K}_{\mathrm{E}}$ and $\mathrm{K}_{\mathrm{EC}}$ and the output scaling factor $\mathrm{K}_{U}$ have a great influence on the control effect during the control process [3].

The larger the $\mathrm{K}_{\mathrm{E}}$, the faster the response; The larger the $\mathrm{K}_{\mathrm{EC}}$, the slower the response speed and the better the control effect. The larger the $\mathrm{K}_{\mathrm{U}}$, the faster the response speed and the stronger the control effect; However, when the selected $\mathrm{K}_{\mathrm{U}}$ is too large, it is prone to oscillation, which is not conducive to control. Therefore, the selection of $\mathrm{K}_{\mathrm{E}}, \mathrm{K}_{\mathrm{EC}}$ and $\mathrm{K}_{\mathrm{U}}$ should be appropriate [4].

The fuzzy domain subset of $\mathrm{E}$ is $[-6,6]$, and the fuzzy domain subset of EC is $[-6,6]$. Generally speaking, in order to improve the control accuracy, the number of elements in the basic domain is usually increased [5]. The basic domain of fuzzy control is divided into 13 parts, and the fuzzy domain is defined as the discrete domain of finite integers:

$\mathrm{N}=\{-6,-5,-4,-3,-2,-1,0,1,2,3,4,5,6\}$ The input value triangle membership function is used to determine the range of the input value according to the scope of the input variable. The fuzzy classification method is divided into 7 fuzzy sets, which are: (PB), (PM), (PS), (zero),(NS), (NM) and (NB), and the fuzzy domain comparison table is obtained, as shown in table 1. 
Table 1 Table of fuzzy domain comparison

\begin{tabular}{cccccccc}
\hline & PB & PM & PS & Z0 & NS & NM & NB \\
\hline-6 & 0 & 0 & 0 & 0 & 0 & 0.2 & 1.0 \\
-5 & 0 & 0 & 0 & 0 & 0 & 0.7 & 0.8 \\
-4 & 0 & 0 & 0 & 0 & 0.2 & 1.0 & 0.4 \\
-3 & 0 & 0 & 0 & 0 & 0.7 & 0.7 & 0.1 \\
-2 & 0 & 0 & 0 & 0 & 1.0 & 0.2 & 0 \\
-1 & 0 & 0 & 0 & 0.5 & 0.9 & 0 & 0 \\
0 & 0 & 0 & 0 & 1.0 & 0 & 0 & 0 \\
1 & 0 & 0 & 0.9 & 0.5 & 0 & 0 & 0 \\
2 & 0 & 0.2 & 1.0 & 0 & 0 & 0 & 0 \\
3 & 0.1 & 0.7 & 0.7 & 0 & 0 & 0 & 0 \\
4 & 0.4 & 1.0 & 0.2 & 0 & 0 & 0 & 0 \\
5 & 0.8 & 0.7 & 0 & 0 & 0 & 0 & 0 \\
6 & 1 & 0.2 & 0 & 0 & 0 & 0 & 0 \\
\hline
\end{tabular}

For the fuzzy data information obtained after fuzzy processing, the computer needs to control the data information according to a series of if-then type fuzzy condition statements in the database. Fuzzy rules are usually summarized and extracted from a large number of practices. Fuzzy language variables are combined with numerical algorithm analysis, based on the manual control of parents' time experience and knowledge accumulation[6].

For dual input single output, usually:

$\mathrm{RN}$ : IF e is An and e $\mathrm{c}$ is $\mathrm{BN}$ then $\mathrm{u}$ is $\mathrm{CN}$ Where, $\mathrm{A}_{\mathrm{i}}$, $\mathrm{B}_{\mathrm{i}}, \mathrm{C} \mathrm{i}$, are the language values corresponding to e, e $\mathrm{c}$ and $u$ in rule $I$, and $R_{i}$ is the control rule $I$.

The implied fuzzy relation is: $\mathrm{R}_{\mathrm{i}}=\left(\mathrm{A}_{\mathrm{i}} \times \mathrm{B}_{\mathrm{i}}\right) \times \mathrm{C}_{\mathrm{i}}$ Finally, for each group of input $\mathrm{e}$ and $\mathrm{e} c$, the corresponding output $\mathrm{u}$ is calculated and expressed in table form to generate a fuzzy query table and complete the intelligent control process of variable pitch.

\section{2 optimize control rules}

For the no-load grid-connection system of wind turbine, it is highly nonlinear and needs to optimize the control rules with the help of RBF neural network [7]. When the number of intelligent control rule sets is equal to the number of hidden layers in the RBF network, the weights in the neural network correspond to the parameters in the rule library. Using the memory characteristics of neural network to remember rules, and using the learning function of neural network to adjust the control rules to achieve the purpose of optimization. The neural network fuzzy control model is shown in figure 3 .

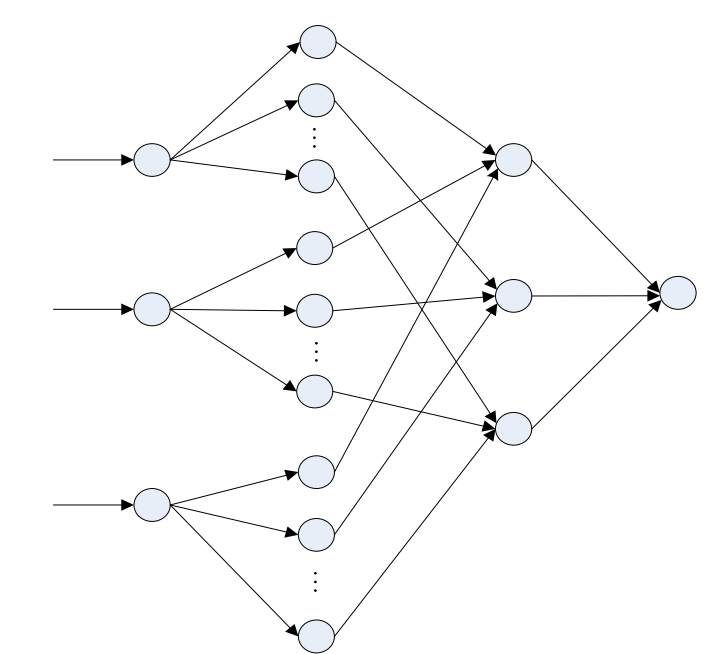

The input layer Membership function layer Rule layer Output layer

Figure 3 Intelligent control model based on RBF neural network

Based on the fuzzy reasoning realized by the neural network structure, the generated model neural control has the function of nonlinear control and the ability of self-learning and self-adaptation of the neural network. The initial control rules are obtained through the nearest neighbor clustering algorithm, and then the parameters of the control rules are input into the neural network for parameter adjustment [8]. In the algorithm, the first data is first used as the clustering center of the first group. If the distance between a data and the clustering center is less than a certain expected value, the data is put into the group. Otherwise, set the data as the clustering center for the new cluster

\section{3 realize intelligent control}

The control method is realized through the controller. The intelligent control method is applied to the controller to obtain the power intelligent controller, which outputs 
the expected power value and effectively controls the no-load grid-connection of the wind turbine. The generator power control is shown in figure 4.

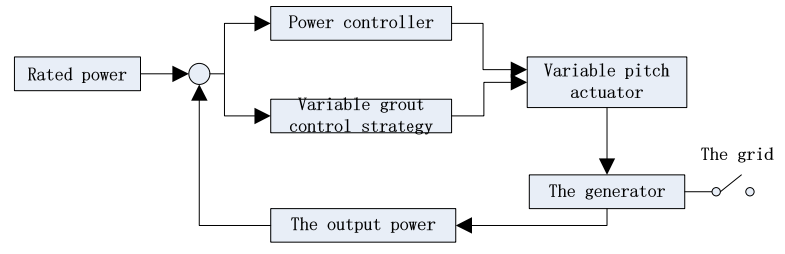

Figure 4 Generator power control

Since the control generator variable pitch also includes other control rings, only the power intelligent control part of the research is shown. Through the intelligent controller combined with the control strategy, the variable pitch actuator is controlled. The variable pitch control strategy is shown in figure 5.

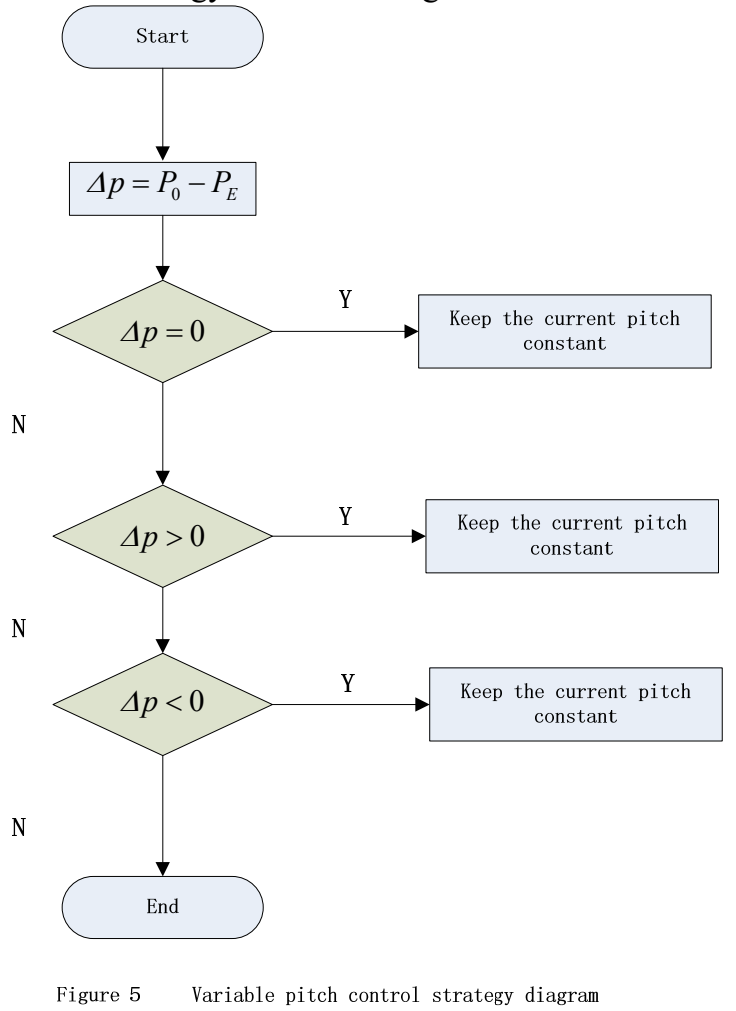

Thus, the design of intelligent control method for no-load grid-connected wind turbine is completed.

\section{Conclusion}

In order to solve the problem of the stability and accuracy of the wind turbine when it is connected to the grid without load, an intelligent control method is designed, which USES the characteristics of the intelligent control to adapt to the nonlinear system and combines the learning ability of the neural network to optimize the control rules, improve the self-learning ability, improve the intelligent control effect and realize the intelligent control.

\section{References}

1. Hui Qi, Quancheng Pan. No-load grid-connection control and experimental study of doubly-fed wind power simulation system [J]. Electrical automation, 2008, 40(6) : 34-37.

2. Haofeng $\mathrm{Wu}$, Xiangdong Wang, Shujiang Li. A new method of maximum wind energy capture for fuzzy control wind turbine $[\mathrm{J}]$. Electronic design engineering, 2017,25 (18) : 147-151.

3. Wenjuan Zhang. Fuzzy control of no-load grid-connected doubly-fed wind power generation with self-adjusting factor [J]. Machinery and electronics, 2008, 36(5) : 52-55.

4. Dongdong Zhang, Shunjie Han, Jiawen Yu, et al. Grid-connected operation control and simulation of doubly-fed wind turbine [J]. Science and technology innovation and application, 2008, 236(16) : 16-18.

5. Yanling Lv, Xi Feng, Bo Zhu, et al. Study on BP neural network connection strategy of doubly-fed wind turbine $[\mathrm{J}]$. Journal of Harbin university of science and technology, 2017,22 (5) : 40-45.

6. Zhichao Yu, Shuai Liu, du Calvin. Study on grid-connected control of wind power generation based on neural network [J]. Electronic technology,8, 347(8) : 93-95+99.

7. Huiqin Li, Ying Sun, Junjie Wang. Improved association mining algorithm based on fuzzy partition clustering $[\mathrm{J}]$. Microelectronics and computers, 2008, 35(3) : 130-134.

8. $\mathrm{Yu} \mathrm{Fu}$. Association rule optimization algorithm based on fuzzy clustering [J]. Computer nerd, 2017,57 (5) : 121-123.

9. Liang Diao, Dan Wang, Lei Guo, et al. Neural network integrated sliding mode control for no-load grid-connection of doubly-fed generators [J]. Journal of solar energy, 2017,38 (12) : 15-19.

10. Jinhui Zeng, Zhifeng Sun, lei min, et al. The improved PR controller is applied to doubly-fed wind power generation system [J]. Power electronics technology, 203, 53(02) : 93-96.

11. Jianfeng Dai, Yi Tang, Linan Qui, et al. Research on coordinated optimal control of solar thermal and wind power generation $[\mathrm{J}]$. Computer simulation, 2017,34 (10) : 73-77.

12. Zhaoyan Xuan, Zhenyu Ma, Huicheng Jing, et al. Overview of control strategies for grid-connected inverter in small wind power generation [J]. Electrical transmission, 2017,47 (9) : 44-49.

13. Jianfeng Yang, Yang Gao, Yuzhong Niu, et al. PIR grid-connected control of three-level wind power system under unbalanced grid [J]. Science and technology bulletin, 2018, (3) : 115-119.

14. Weihua Jiang, ma Chao Li, Xianfeng Zheng. Study on three-level grid-connected wind power generation system based on sliding mode control 
[J]. Power capacitors and reactive power compensation, 2017,38 (3) : 162-166.

15. Linjing Hu, Peipei Li, Aoyu Ton, et al. Research on reactive power support of mmc-hvdc grid-connected wind power system [J]. Power capacitors and reactive power compensation, 2008, 39(2) : 119-124. 